\title{
A EDUCAÇÃO À DISTÂNCIA NO CENÁRIO ATUAL: SUAS CARACTERÍSTICAS E IMPLICAÇÕES
}

\author{
E-LEARNING NOWADAYS: CHARACTERISTICS AND IMPLICATIONS \\ EDUCACIÓN A DISTANCIA EN EL ESCENARIO ACTUAL: SUS \\ CARACTERÍSTICAS E IMPLICACIONES
}

\author{
Simone Cristina Mussio \\ Doutora em Linguística e Língua Portuguesa - UNESP \\ Docente da Faculdade de Tecnologia de Jahu \\ Docente das Faculdades Integradas de Jaú \\ E-mail: simussio@yahoo.com.br \\ Valéria Cristiane Validório \\ Doutora em Estudos Linguísticos - UNESP \\ Docente da Faculdade de Tecnologia de Jahu \\ E-mail: valtradutora@ hotmail.com \\ Vera Maria Ferro Merlini \\ Especialista em Psicopedagogia no Processo Ensino-Aprendizagem - CEUCLAR \\ Docente da Faculdade de Tecnologia de Jahu \\ E-mail: veramerlini@hotmail.com
}

\section{RESUMO}

Tendo em vista o crescimento da Educação à Distância na atualidade, a qual se baseia em um modelo de aprendizagem, ancorado em modos dinâmicos e interativos de como pessoas em geral adquirem novos conhecimentos e competências, este artigo objetiva refletir sobre suas práticas e métodos, assim como mostrar a importância do professor (mediador-tutor) neste contexto de aprendizagem virtual. Logo, tenciona retratar as características que envolvem este tipo de ensino, de modo a definir alguns processos significativos para a formatação de um curso à distância.

Palavras-chave: Ensino à Distância. Professor (mediador/tutor). Ambientes virtuais. Ensinoaprendizagem.

\begin{abstract}
Considering e-learning growth nowadays, which is based on a learning model, build in dynamic and interactive modes of how general people develop new knowledge and competence, this paper aims at reflecting on its practices and methods, as well as showing the importance of the professor (mediator-tutor) in this virtual learning context. Thus, this paper aims at presenting the characteristics that involve this kind of teaching, in order to define some significant processes to format an e-learning course.
\end{abstract}

Keywords: e-learning. Professor (mediator/tutor). virtual learning environments. teachinglearning.

\section{RESUMEN}

Dado el crecimiento actual de la educación a distancia, que se basa en un modelo de aprendizaje, anclado en formas dinámicas e interactivas en las que las personas en general adquieren nuevos conocimientos y habilidades, este artículo tiene como objetivo reflexionar sobre sus prácticas 
y métodos, así como cómo mostrar la importancia del profesor (tutor-mediador) en este contexto de aprendizaje virtual. Por lo tanto, tiene la intención de retratar las características que involucran este tipo de enseñanza, con el fin de definir algunos procesos significativos para el formato de un curso de aprendizaje a distancia.

Palabras clave: Aprendizaje a distancia. Profesor (mediador/tutor). Entornos virtuales. Enseñanza-aprendizaje.

\section{INTRODUÇÃO}

Dentro e fora das salas de aula, a Educação tem mudado por causa da aceleração da produção científica e tecnológica; seja pela facilitação ao processo de internacionalização do ensino, pela presença de novas tecnologias no processo ensino-aprendizagem ou pela criação de novas metodologias, incluindo o ensino à distância, o qual está cada dia mais interativo e abrangente (PORTO \& RÉGNIER, p. 2003).

Os cursos superiores no novo milênio, por sua vez, passam a assumir o papel específico de transformadores ou modificadores da sociedade global, pois são o instrumento através do qual milhões de jovens têm a chance de se preparar para assumirem seus papéis na comunidade, tornando-se, por meio de novos conceitos adquiridos nos bancos escolares, pessoas habilitadas, autônomas e críticas em uma sociedade cada vez mais competitiva, na qual o saber é sinônimo de poder.

Mas, para tanto, deve-se estabelecer que a aprendizagem significativa na Instituição do Ensino Superior (IES) pressupõe troca de informações, disponibilidade para resolver problemas e aprender assuntos novos, articulação entre o que se sabe e o que se está aprendendo. E pressupõe que os conhecimentos vão ganhando sentido quando são experimentados em contextos reais, na interação com as práticas sociais. Cremos, assim, que as aprendizagens significativas compartilhadas são integrações construtivas de pensamentos, sentimentos e ações.

Sendo assim, no século XXI, não basta aprender apenas usando-se métodos e metodologias tradicionais: é preciso a arte de traduzir todo o conhecimento em ação, em um ambiente motivador e que possibilite ir além da limitação que a sala de aula impõe: o ciberespaço.

Deste modo, este artigo tem como objetivo refletir sobre a questão da educação à distância neste contexto tecnológico instaurado. Busca, assim, retratar a importância da Educação à Distância, bem como mostrar a importância do professor (mediador-tutor) neste ambiente virtual de aprendizagem ao estimular a aprendizagem colaborativa. 


\section{A IMPORTÂNCIA DA EDUCAÇÃo À DISTÂNCIA}

De com a Universidade Aberta do Brasil - UAB (2008), a Educação à Distância (EaD) é a modalidade de ensino na qual se utiliza da mediação didático-pedagógica nos processos de ensino e aprendizagem, e ocorre com a utilização de meios e tecnologias de informação e comunicação, envolvendo estudantes e professores no desenvolvimento de atividades educativas em lugares ou tempos diversos. Em virtude de constituir uma forma de atuação que utiliza intensivamente os recursos das TIC (Tecnologias de Informação e Comunicação), envolve, comumente, o alto volume de investimentos e o desenvolvimento de programas que atendam às necessidades específicas deste formato. Assim, as instituições precisam investir em recursos materiais, tecnológicos e competência, o que permite a cada instituição maximizar suas capacidades, da mesma forma que possibilita a sinergia entre os envolvidos no processo de ensino aprendizagem à distância, provendo às populações-alvo maiores oportunidades educacionais, especialmente em situações adversas, levando-se em consideração a distância do campus tradicional, situação socioeconômica, entre outros.

Desse modo, a EaD surge como uma alternativa de ensino abrangente, pois é uma modalidade de ensino/aprendizagem que pressupõe o rompimento da relação face a face entre alunos e professores. Como é uma modalidade de ensino que tem por base esse fato, elementos, como os meios de comunicação, os materiais didáticos, a tutoria acadêmica, entre os elementos mais importantes nesse tipo de sistema, assumem um papel central nos processos educativos (em função da necessidade de mediá-los). Isso não significa que os sistemas constituídos para um processo de ensino-aprendizagem baseado na $\mathrm{EaD}$ impliquem novas formas de aprendizagem. Significa, simplesmente, que novos ambientes de aprendizagem podem se constituir de maneira independente da relação professor-aluno que conhecemos. Quando se trata da EaD, esses novos ambientes devem ser considerados também no processo avaliativo. Dessa maneira, material didático, meios de comunicação, tutoria e organização de meios acabam por influenciar os processos de ensino-aprendizagem sem, no entanto, modificar seus fundamentos epistemológicos.

De acordo com Maluf (apud AUSUBEL 2008), para que haja aprendizagem significativa é necessário que:

a) o aprendiz tenha disposição para aprender: se quiser memorizar a atividade arbitrariamente e literalmente, então a aprendizagem será mecânica; 
b) a atividade a ser aprendida seja potencialmente significativa: significado lógico, que depende somente da natureza da atividade; e significado psicológico, isto é, uma experiência que cada educando tem. Cada ser aprendente faz uma filtragem das atividades que têm significado ou não para si próprio.

A importância da aprendizagem dos processos cognitivos e a implementação de técnicas capazes de favorecer uma aprendizagem devem ser significativas, revelando-se em todos os domínios abarcados pela escola. Quanto maior for o conhecimento dos modos de representação do saber e dos processos cognitivos, quanto maior for a consciência dos educandos neste processo, tanto mais terão vontade de aprender, tanto mais serão capazes de encarar a Instituição como a continuação da sua casa, do seu meio ambiente.

Embora na Educação à Distância não se tenha, de maneira intensa, a participação do aluno em um ambiente físico, uma vez que suas aulas são mediadas à distância, o aprendente, a partir do momento em que escolheu determinada Instituição de Ensino para a realização de seu curso à distância, sentiu empatia e confiança na entidade escolhida para ali permanecer durante todos os anos de sua graduação, por exemplo. Desse modo, tem-se a responsabilidade da instituição em promover práticas sérias e coerentes para que este filtro positivo estabelecido com o aluno não seja rompido.

É consensual entre os estudiosos que a docência no Ensino Superior exige não apenas um domínio de conhecimentos e experiência a serem transmitidos por um mestre, mas principalmente precisa deixar de lado as características amadorísticas e adotar um profissionalismo semelhante àquele exigido para o exercício de qualquer profissão (ARAÚJO, 2002). Na EaD, mesmo diante da distância estabelecida, o aluno avalia o seu professor (mediador/tutor) quanto ao seu conhecimento, postura, assiduidade no acesso ao sistema no qual o curso está inserido.

\section{A RELEVÂNCIA DO PROFESSOR (MEDIADOR-TUTOR) NA EaD}

Como apontado por diversos autores, vivemos um período de transição em que crenças absolutistas e de neutralidade da ciência, assim como de diversos pressupostos da modernidade, que vigoraram como verdades absolutas durante muito tempo, passam a ser questionados. A formação do docente não pode desvincular-se desse processo de transformação mundial e, sofre, na verdade, a influência deste de maneira significativa.

No meio acadêmico, uma grande preocupação vista é com a formação contínua dos professores. O problema é que, ainda hoje, a prática usual nas universidades concorre para 
desassociar as atividades de pesquisa e ensino, sobretudo devido à ênfase na condução de pesquisas, uma vez que os critérios de avaliação de produtividade e a qualidade docente concentram-se na produção acadêmica destes professores.

Assim, ensino e pesquisa passam, muitas vezes, a ser atividades concorrentes, todavia, mesmo na EaD, deve-se valorizar esses dois segmentos. A atividade docente deve ser enfatizada, com o aprimoramento de cursos e capacitações, por exemplo. É possível afirmar, com convicção, que sem estudo é impossível ser um bom professor, e esse estudo é um trabalho sistêmico. Contudo, também deve ser foco de observação o incentivo à pesquisa. Não é porque a graduação é à distância que os professores não devem se preocupar com o aprimoramento dos estudos e pesquisa, principalmente nesta área de atuação prenhe de materiais e diversas situações de análise.

Quando o professor elabora um plano de ensino e faz o planejamento de uma unidade de estudo, ele relaciona conteúdos, define competências a serem alcançadas e habilidades a serem desenvolvidas. Assim, a avaliação geral de desempenho do processo de ensino/aprendizagem deve estabelecer as estratégias para que intervenções sejam definidas e disponibilizadas, quando necessárias, fornecendo informações ao gestor (diretor e coordenadores) sobre os níveis de aprendizagem e análise das condições em que o ensino é realizado.

Um curso on-line deve, antes de tudo, privilegiar o diálogo e a interação, sendo o educador um organizador de situações de aprendizagem, de acordo com aspectos relevantes às características do educando que utilizará os materiais. Para isso, deve levar em conta fatores linguísticos (clareza, simplicidade e familiaridade da linguagem); fatores instrucionais (importância do conteúdo, adequação de exemplos e analogias); revisão; efetividade da aprendizagem; satisfação; interação com o programa; diferenças individuais; fatores de interatividade com o software e com as pessoas; conhecimento, habilidades e atitudes do instrutor; fatores contextuais (culturais).

O ambiente virtual deve ser visto como um lugar de práticas pedagógicas, geradas a partir de atividades docentes, as quais estimulam o desenvolvimento de uma educação transformadora, se esta for baseada em um conhecimento que permita ao professor interpretar, refletir e dominar criticamente a tecnologia. O resultado disso tende a ser uma mudança positiva na autoestima dos professores, como na dos alunos.

$\mathrm{O}$ professor precisa estar atento às atividades propostas, precisa ser criativo para permear toda a construção do conhecimento e apaziguar as situações que venham a ocorrer no 
ambiente virtual. A presença da máquina (computadores, tablets, smartphones, etc.) leva o professor a questionar qual postura adotar frente à revolução de ideias e metodologias, como também o faz refletir sobre quais são as competências técnico-pedagógicas necessárias para, assim, explorar as potencialidades da máquina como ferramenta educacional.

A formação de professor para o uso da tecnologia deve, então, ultrapassar os aspectos cognitivos em si e integrar aspectos subjetivos como: respeito, confiança, aceitação, desprendimento, para desenvolver uma relação de reciprocidade, estimulando cada vez mais a criatividade e autonomia diante da máquina. É de suma importância que o professor planeje e organize as estratégias de ensino e esteja imbuído de uma nova perspectiva para seu papel: o de ser ele mesmo, um mediador pedagógico, um professor-pesquisador (MASETTO, 1998).

A atuação do docente é, portanto, fundamental. O professor é um mentor que está em constante crescimento intelectual e deve saber utilizar sabiamente o ambiente da EaD como um sistema que hoje está completamente perpetuado em nossa sociedade.

Como a EaD propicia um estudo em ambiente doméstico, social ou profissional, permitindo que o estudante escolha os horários em que vai estudar, tal característica pode ser uma qualidade valiosa que a distingue do ensino tradicional. No entanto, por outro lado, como possui mais estímulos concorrenciais e depende diretamente de algumas aptidões intrínsecas do aluno (capacidade de concentração e organização, entre outras) pode favorecer a evasão escolar. Daí a grande importância de um professor (mediador/tutor) que esteja sempre presente, buscando motivar os alunos constantemente, de modo a auxiliá-los em suas necessidades.

Na visão sistêmica ou holística, analisada por Santinello (apud BEHRENS, 2005), o professor necessita galgar caminhos alternativos que alicercem uma ação docente relevante, significativa e competente, trabalhar o censo de cidadania de seus alunos também, analisandose e, sobretudo, exercendo uma função de mediador do conhecimento. Os docentes devem entender que o professor de cursos a distância pode ser considerado uma equipe, a qual inclui um coordenador, um autor, um técnico, um artista gráfico, um professor (mediador/tutor), etc. Muito mais do que um professor, é uma instituição que ensina a distância; por isso muitas definições de EaD se ancoram na ideia de que o ensino é sempre planejado e coordenado por uma instituição (MAIA \& MATTAR, 2007).

Logo, o engajamento do professor deve ocorrer não apenas com as ferramentas tecnológicas que sustentam este tipo de educação, mas com pesquisas e pessoas que visam proporcionar novas formas de se produzir conhecimento e de estabelecer relações sociais. 


\section{OS AMBIENTES VIRTUAIS DE ENSINO E APRENDIZAGEM}

A produção por $\mathrm{EaD}$ é, geralmente, atribuída à equipe que se encarrega da preparação de materiais educacionais para diferentes mídias. Assim, a composição e o funcionamento de equipes multidisciplinares para a sua produção refletem os processos de uma instituição, seja acadêmica ou corporativa, em sintonia com as metas estabelecidas segundo os valores, princípios e critérios definidos pelas próprias instituições (LITTO \& FORMIGA, p. 2009)

Na Figura 1, observa-se que uma boa aula, elaborada por um professor bem preparado, motivado, experiente, faz a diferença nos resultados obtidos na prática educativa, independente da faixa etária do aluno e do nível de escolaridade, pois a avaliação necessita de objetivos e critérios, estabelecendo-se procedimentos que visem o melhor desempenho dos alunos.

Figura 1 - A importância de uma boa aula

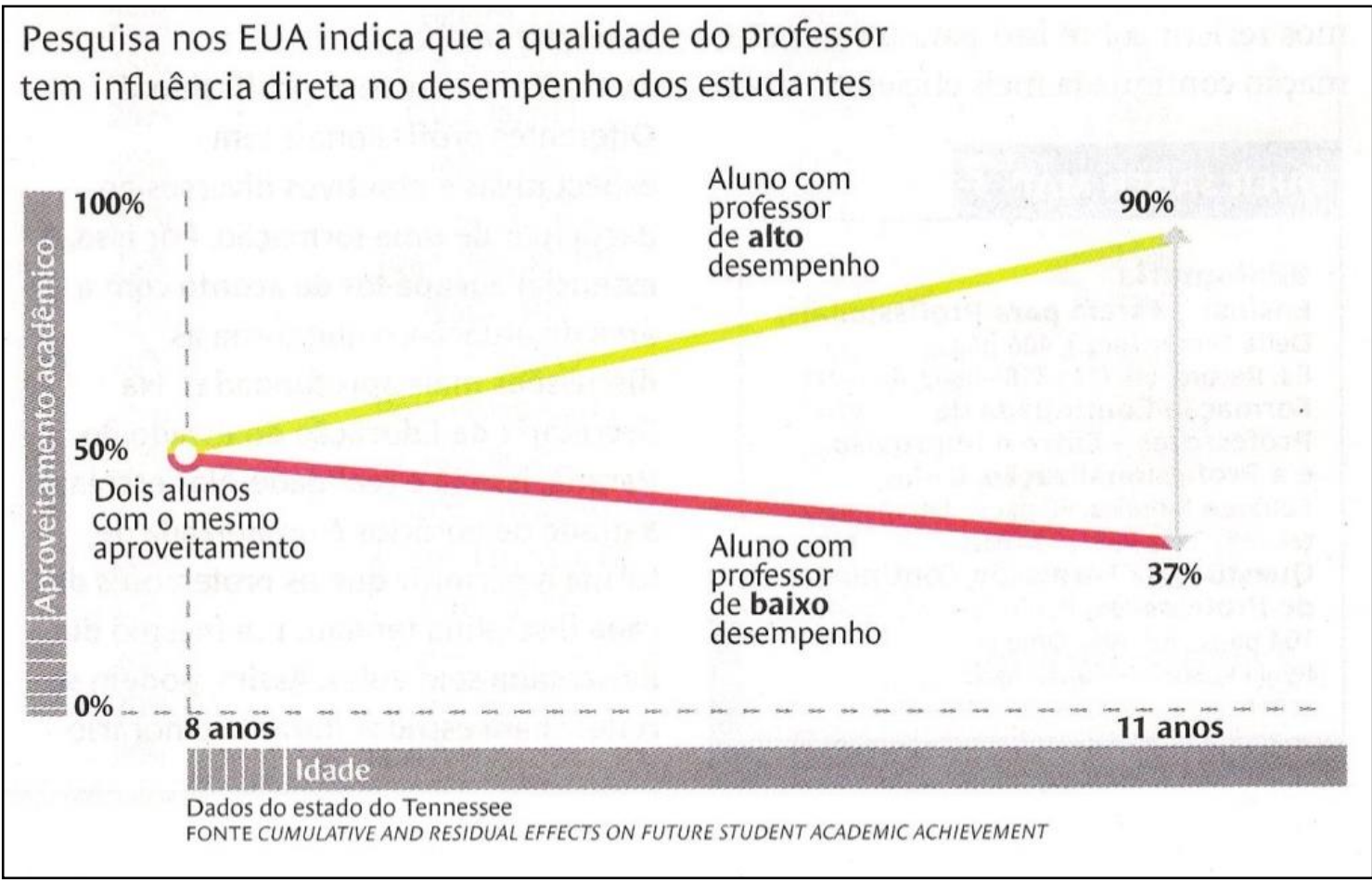

Fonte: Nova Escola Out. 2008, p. 58

A estruturação de cursos on-line, baseada em uma pedagogia diferenciada, requer, além de ferramentas, uma postura pedagógica inovadora que permita a participação e cooperação de aprendizes na construção de conhecimento. Deve-se primar pelo equilíbrio entre o autoestudo e a interação dos participantes, caracterizado pela aprendizagem colaborativa, e incentivados por um professor (mediador/tutor) atuante, afinal, como foi visto na figura acima, a presença do professor é fundamental para que se estabeleça um ensino de qualidade. 
Mas fazendo alusão à composição do curso em si, a criação de uma atividade compreende: estratégia didática, domínio e recurso. Assim, para implementação de estratégias de ensino e aprendizagem em ambiente virtual (AVA), três elementos são essenciais: a tecnologia, a comunicação e linguagem e a aprendizagem, incluindo a utilização de recursos virtuais e não-virtuais, posteriormente postados e compartilhados com os colegas (LITTO \& FORMIGA, 2009).

Na Figura 2, demonstra-se, esquematicamente, o processo de montagem de um curso on-line.

Figura 2 - Processo de Montagem de um Curso On-line.

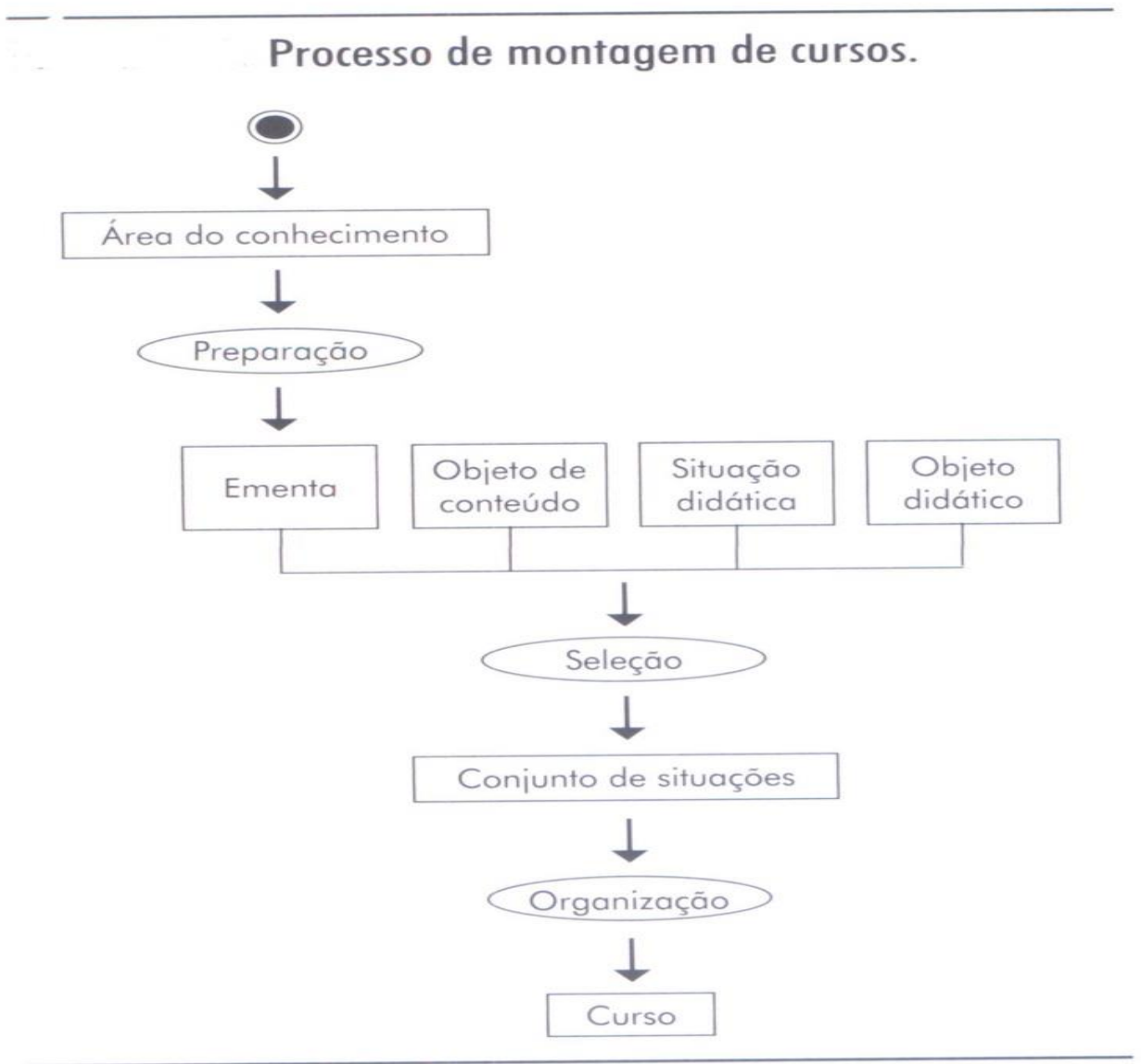

Fonte: LITTO \& FORMIGA (org.): 2009

Para conseguir elaborar um curso on-line, etapas devem ser seguidas, pois a utilização da informática no processo educativo não significa simplesmente disponibilizar hardware e software. A utilização de Novas Tecnologias na Educação com qualidade necessita de um educador, de um orientador para que as informações que estão disponíveis sejam direcionadas para a aprendizagem dos usuários. 
Para isso, na figura 3, propõe-se um modelo de etapas para implementação de atividades para aprendizagem em ambientes virtuais. Note-se que é necessária uma interação entre as ações do professor e os recursos tecnológicos disponibilizados para se alcançar os objetivos.

Figura 3 - Modelo de Etapas para Implementação de Atividades em AVAs

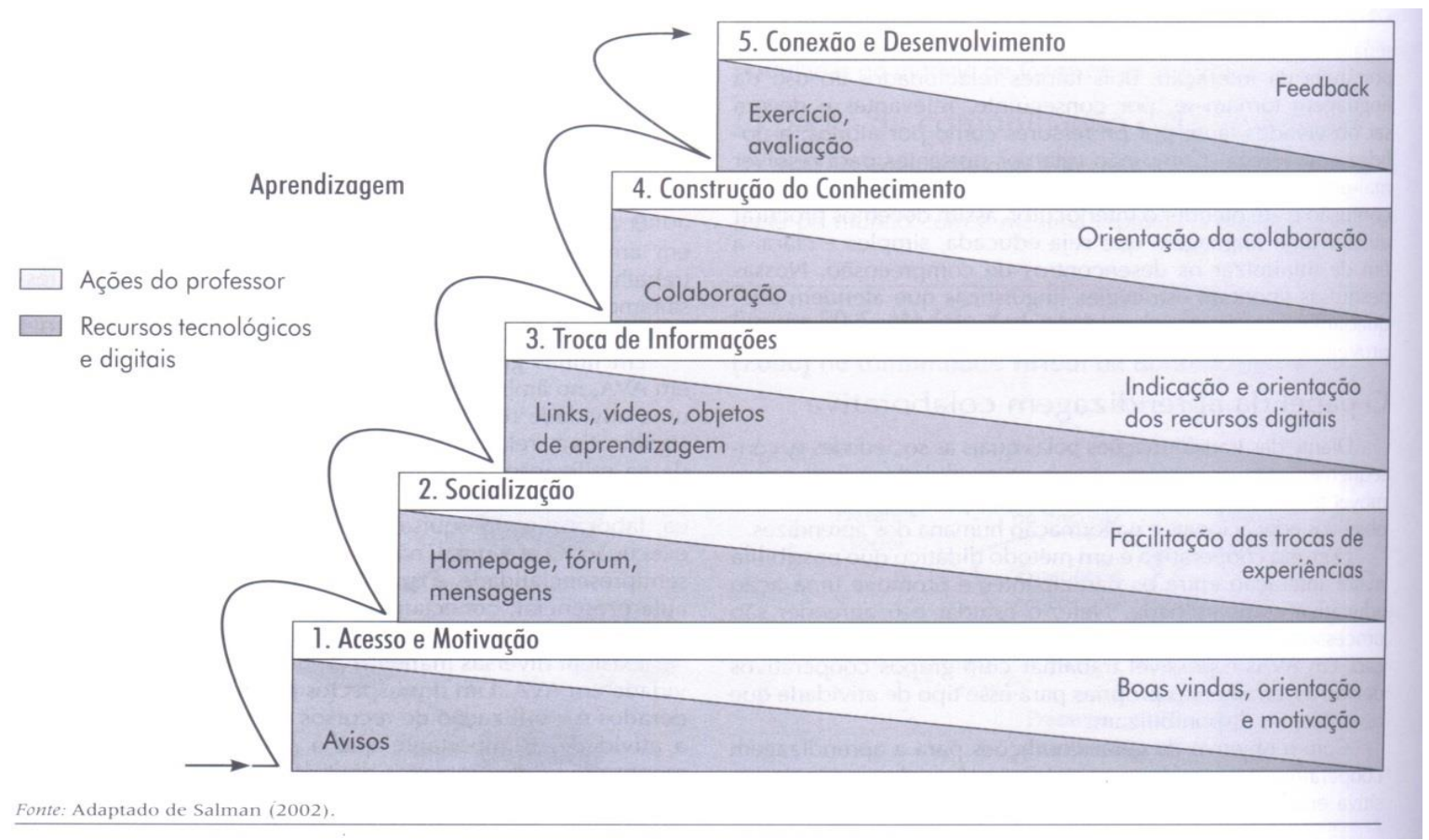

Fonte: LITTO \& FORMIGA (org.): 2009

Para se implantar um projeto de informática educativa, é necessário: diagnóstico tecnológico da escola, do professor e do aluno; plano de ação; capacitação dos docentes; conhecimento e pesquisa de softwares; elaboração do projeto pedagógico com o uso da informática; implantação e avaliação do projeto e replanejamento (TAJRA, 2000).

Para completar o processo, a composição de uma equipe de produção para $\mathrm{EaD}$, conforme suas áreas profissionais e competências inclui:

- Equipe Gestora - composta de profissionais que definem, organizam e acompanham as atividades do projeto de $\mathrm{EaD}$;

- Equipe de Autores ou Conteudistas - profissionais que desenvolvem os conteúdos, selecionando e reunindo os materiais, organizando e propondo dinâmicas, estratégias e recursos pedagógicos a serem desenvolvidos; 
- Equipe Pedagógica - assume diferentes papéis: desenvolver pesquisas em consonância com os cursos; concepção, produção e avaliação dos mesmos; acompanhamento e formação de tutores, entre outros;

- Equipe de design instrucional - profissional com perfil interdisciplinar (educação, comunicação e tecnologia), articulando várias funções;

- Equipe de Arte - profissionais responsáveis por animações, ilustrações, bem como navegabilidade, usabilidade e conformidade com os padrões de desenvolvimento de materiais para $\mathrm{EaD}$;

- Equipe de tutores ou Mediadores da Aprendizagem - profissionais que acompanham a turma de alunos durante o período da atividade;

- Equipe de Monitoria Pedagógica - profissional que acompanha a trajetória de aprendizagem;

- Equipe de Suporte Técnico - monitor técnico que acompanha os participantes quanto as dificuldades tecnológicas;

- Equipe Tecnológica - responsável pela gestão das tecnologias envolvidas nos processos educacionais (ambiente virtual de aprendizagem, base de dados do curso, gerenciamento e montagem de turmas);

- Alunos - agentes integrantes das equipes de produção.

Cabe ressaltar que, em determinados projetos, sob algumas circunstâncias, um mesmo profissional pode assumir e acumular diversos papéis, como autor, designer educacional, tutor, dentre outros, mas sempre em equipe (LITTO \& FORMIGA, 2009).

O mercado necessita de pessoas com visão pluralista, adaptáveis, flexíveis, com habilidades que extrapolem as funções executadas rotineiramente. Mas as IEs não conseguirão atender as necessidades da sociedade se não mudar as práticas acadêmicas engessadas por práticas sociais colaborativas. 


\section{CONSIDERAÇÕES FINAIS}

Em virtude das novas oportunidades oriundas na modernidade, especialmente de atuação profissional em campos inéditos, constata-se a necessidade de novas modalidades de acesso às inovações e ao conhecimento, capaz de conferir melhores condições de competitividade aos grupos, empresas e indivíduos, em diferentes situações da vida contemporânea.

Desse modo, é possível observar que o cenário atual demanda reflexões e revisões constantes de métodos e metodologias que envolvem o ensino/aprendizagem, pois a prática pedagógica não pode ficar em descompasso com a realidade sócio-educacional-cultural do século XXI no Brasil. Para tanto, a EaD constitui uma ferramenta viável, apresentando uma metodologia diferenciada que prevê o aluno como agente ativo na aquisição do conhecimento. Desse modo, cabe a ele transformar-se em agente produtor do conhecimento, desmistificando o papel de agente passivo, tido apenas como receptor de conteúdos. No entanto, para essa construção do processo de ensino-aprendizagem na $\mathrm{EaD}$, não se pode esquecer a ação dos professores (mediadores/tutores) na orientação e assessoramento dos discentes envolvidos.

$\mathrm{Na}$ sociedade do conhecimento e da aprendizagem, nada mais significativo que trabalhar com tecnologias e meios reais que permitem ao aluno adotar posições variadas de interpretação e estimular a vivência de múltiplos papéis em contextos realistas. Por meio da EaD, o professor (mediador/tutor) pode, assim, estimular a busca de soluções em grupo, por meio do diálogo e do estudo sistemático, assim como promover o desenvolvimento de habilidades e destrezas cognitivas complexas, como projetar, avaliar, analisar, sintetizar, investir nos processos de memória (armazenamento e recuperação de experiências e informações) que subsidiam a aprendizagem. Além disso, é possível ainda desenvolver flexibilidade cognitiva na aprendizagem, favorecendo o pensamento crítico e a metacognição, explorando-se a capacidade espontânea de reestruturar o próprio conhecimento diante de situações em constante mudança, pela forma de apresentar e representar o conhecimento, ou pelos processos mentais que nela operam, facilitando a participação social e a inserção profissional.

Nesse sentido, como elementos-chave nesse processo de transmutação global, tanto as IEs quanto os professores devem adaptar-se às inovações relacionadas ao avanço científicotecnológico; às alterações na organização do processo produtivo; à sociedade de informação; aos processos de globalização da economia e a alterações na relação dos sujeitos com o conhecimento. 


\section{REFERÊNCIAS BIBLIOGRÁFICAS}

ARAÚJO, Teresa Regina. A formação do professor universitário: um convite à reflexão. Revista do Ensino Superior do Catalão - CESUC, Ano IV, n 7, $2^{\circ}$ semestre de 2002. Disponível em http://www.cesuc.br/revista/ed-2/FORMACAO_DO_PROFESSOR.pdf. Acesso em 18 set. 2008.

FUNDAÇÃO VICTOR CIVITA. Revista Nova Escola. Out/2008.

LITTO, F.M. \& FORMIGA, M.M.M.(org) Educação a Distância: o Estado da Arte. SP, Pearson Education do Brasil, 2009.

MAIA, C. \& MATTAR, J. ABC do EaD. $1^{\circ}$ Ed., SP, Pearson Prentice Hall, 2007.

MALUF, A. C. M., Atendimento Psicopedagógico No Ensino Superior Buscando Condições Para Aprendizagem Significativa.

http://www.psicopedagogia.com.br/artigos/artigo.asp?entrID=1094. Acessado em 04 dez. 2008 .

MASETTO, Marcos (org.). Docência na Universidade. Campinas, SP: Papirus, 1998.

MINISTÉRIO DA EDUCAÇÃO E CULTURA (MEC) Regulamentos, Decretos, Estatisticas: Disponível em <//http://www.portal.mec.gov.br//> Último acesso em. Nov. 2008.

Universidade Aberta do Brasil - UAB. Disponível em:

http://uab.capes.gov.br/index.php?option=com_content\&view=article\&id=102:sobreeducacao-a-distancia-apresentacao\&catid=25:artigos-uab\&Itemid=57. Acesso em $18 \mathrm{dez}$. 2018.

PORTO, C. \& RÉGNIER, K.. O ENSINO SUPERIOR NO MUNDO E NO BRASIL Condicionantes, Tendências e Cenários para o Horizonte 2003-2025: Uma Abordagem Exploratória. Dezembro, 2003. Disponível em h

http://portal.mec.gov.br/sesu/arquivos/pdf/ensinosuperiormundobrasiltendenciascenarios2003 -2025.pdf. Acesso em 18 ago. 2015.

SANTINELLO, Jamile. O professor universitário usando ambiente de EAD como apoio pedagógico na educação presencial maio 2005 Disponível em

http://www.abed.org.br/congresso2005/por/pdf/119tcc3.pdf > Acesso em 12 set. 2018.

TAJRA, S.M. Informática na Educação - Novas Ferramentas Pedagógicas para o

Professor da Atualidade. 2a . Ed.ver., atual. E ampl. SP, Érica, 2000. 